\title{
Different Psychological States Sustain Drug-Induced Reactivation of Cocaine Conditioned Place Preference in the Mouse
}

\author{
Tangui Maurice ${ }^{*}, 1,2,3,4$, Julie Espallergues ${ }^{1,2,3,4}$, Charleine Zussy ${ }^{1,2,3,4}$, Johann Meunier ${ }^{1,2,3,4}$, \\ Clémence Borys ${ }^{3,4}$, Elodie George ${ }^{3,4}$ and Pascal Romieu ${ }^{3,4,5}$ \\ ${ }^{I}$ INSERM U 710, 34095 Montpellier, France \\ ${ }^{2}$ EPHE, 75017 Paris, France \\ ${ }^{3}$ University of Montpellier II, 34095 Montpellier, France \\ ${ }^{4}$ CNRS FRE 2693, 34095 Montpellier, France \\ ${ }^{5}$ INSERM U 575, 67084 Strasbourg, France
}

\begin{abstract}
Cocaine-seeking behavior can be investigated in rodents using the conditioned place preference (CPP) paradigm. CPP can be extinguished and then reactivated using cocaine priming. To study the role of dopaminergic receptors in CPP reinstatement, CPP was induced in Swiss mice using cocaine $(30 \mathrm{mg} / \mathrm{kg}$ ip) and extinguished with saline. CPP reactivation was examined by treatment with the D1 receptor antagonist SCH23,390 (0.03-1 mg/kg), the D2 antagonist raclopride $(0.1-3 \mathrm{mg} / \mathrm{kg})$ or the D3 antagonist U-99,194A $(20-40 \mathrm{mg} / \mathrm{kg})$, alone or before cocaine $(15 \mathrm{mg} / \mathrm{kg})$. Cocaine priming reactivated CPP up to $220 \%$ of the post-conditioning response. $\mathrm{SCH} 23,390$ and raclopride induced, alone at 0.3 $\mathrm{mg} / \mathrm{kg}$, reactivation of cocaine-induced CPP, but only SCH23,390 blocked the cocaine-induced reactivation. U99,194A failed to promote CPP reactivation alone or to affect the cocaine response. CPP reactivation involving contextual learning could be induced using a single-reconditioning session after extinction. Treatment with cocaine or raclopride, but not $\mathrm{SCH} 23,390$, induced CPP reactivation. Finally, the emotional state of mice was tested during reactivation under drug treatments in the elevated maze procedure and an anxiety state was measured after $0.3 \mathrm{mg} / \mathrm{kg} \mathrm{SCH} 23,390$. These observations showed that in cocaine-conditioned animals and then extinguished, blockade of D1 receptors induces an anxiogeniclike state, able to promote a cocaine-sensitive CPP reactivation. Blockade of D2 receptor promoted a cocaine-mimetic CPP reactivation. Therefore, two different psychological states underlie CPP reactivation by drug priming: a 'drug craving CPP' induced by dopamine systems-mediated anxiety and a 'drug retrieval CPP' promoted by incentive learning processes.
\end{abstract}

\section{INTRODUCTION}

Relapse to drug seeking, even after long-term withdrawal periods, remains a major problem in the treatment of drug addiction [1-3]. Several animal models have been used to evaluate the rewarding properties of drugs of abuse including drug self-administration and conditioned place preference (CPP). Although the CPP procedure cannot modelize the reinforcing properties of drugs or motivation of animal to obtain the drug, it can be used to examine the reinstatement of drug-seeking behavior, which is considered a model of drug relapse.

Cocaine acts as a potent indirect dopamine receptor agonist by inhibiting dopamine reuptake systems. The abused drug therefore increases the neurotransmitter synaptic concentration in mesocorticolimbic neurons, which is believed to intervene in different aspects of goal-directed behaviors and to underlie, at least in part, the neuroplasticity leading to compulsive drug use. Several behavioral procedures, including self-administration and CPP, have been used to examine

*Address correspondence to this author at the INSERM U. 710, University of Montpellier II, cc 105, pl. E. Bataillon, 34095 Montpellier cedex 5, France; Tel: +33/0 4671436 23; Fax: +33/0 4671433 86;

E-mail: Tangui.Maurice@univ-montp2.fr the role of dopaminergic systems in cocaine-related behaviors such as hyperlocomotion, cocaine seeking or intake. In particular, systemic administration of the D1 receptor antagonist SCH23,390 blocked the acquisition, but not expression, of cocaine-induced CPP $[4,5]$. The D2 receptor antagonists (-)-sulpiride or eticlopride had no effect on cocaine-induced CPP $[4,5]$. The selective D3 receptor antagonist SB-277011-A or the partial D3 agonist BP-897 prevented both acquisition and expression of cocaine-induced CPP [6, 7].

Cocaine can induce a place preference, which can be extinguished by dissociating the unconditioned stimulus (cocaine injection) from the conditioned stimulus (the drugpaired compartment) and finally reactivated by: (i) a priming injection of cocaine, (ii) the re-presentation of cocaineassociated cues or (iii) acute stress [8-11]. But it must be noted that this reinstatement of drug-seeking behavior could come from different psychological or emotional states. Furthermore, no study examined the involvement of D1 or D2 dopamine receptor subtypes in reactivation of CPP and only one for D3 receptors [7].

In the present study, we trained Swiss mice using a conditioning dose cocaine in the CPP procedure. After conditioning, the behavioral response was extinguished and CPP reactivation was measured after administration of the D1 
selective receptor antagonist $\mathrm{SCH} 23,390$, the D2 selective antagonist raclopride or the D3 selective antagonist U99,194A alone or together with cocaine. The CPP reactivation was also tested in a drug-free paradigm, i.e. animals were submitted to a single re-conditioning session with cocaine or dopamine ligands and place preference was measured after $24 \mathrm{~h}$. Furthermore, to check the anxiogenic-like effects of the compounds in CPP conditioned/extinguished mice, some conditioned/extinguished animals were tested in the elevated plus-maze test with the same drug treatment as used for CPP reactivation.

\section{METHODS}

\section{Animals}

Male Swiss mice $(\mathrm{n}=288)$, 1-month old and weighing 28-32 g, were purchased from the breeding center of the Faculty of Pharmacy (Montpellier, France). Animals were housed in groups with access to food and water ad libitum, except during behavioral experiments. They were kept in a temperature and humidity controlled animal facility on a $12 \mathrm{~h} / 12 \mathrm{~h}$ light:dark cycle (light off at 20:00). Experiments were carried out between 9:00 and 18:00, in a sound attenuated and air-regulated experimental room, to which mice were habituated at least $30 \mathrm{~min}$ before each experiment. All animal procedures were conducted in strict adherence to the European Council Directive of 24 November 1986 (86609/EEC).

\section{Drugs}

Cocaine hydrochloride was obtained from Cooper (Melun, France). SCH23,390, raclopride and U99,194A were from Sigma-Aldrich (Saint-Quentin Fallavier, France). All drugs were solubilized in physiological saline $(0.9 \%)$. They were injected intraperitoneally (ip) in a volume of $100 \mu \mathrm{l}$ per $20 \mathrm{~g}$ of body weight.

\section{Place Preference Conditioning Procedure}

The apparatus consisted of a polyvinylchloride box divided into two compartments of equal size $(15 \times 15 \times 35 \mathrm{~cm}$ high), the first one with black walls and floor, the second one with white walls and floor. Each compartment presented different floor textures, smooth for the black one and covered by a wire mesh grid for the white. A $60 \mathrm{~W}$ lamp lit the white compartment during all the experiments. A sliding door separated the two compartments. The procedure, detailed in a previous report [11-14] consisted of four different phases: preconditioning (day 1), conditioning (days 2 to 6), extinction (days 8 to 12) and reactivation (day 15 or days 15 and 16).

For the preconditioning phase, each mouse was placed in the white compartment and after $5 \mathrm{~s}$, the sliding doors were raised. The animal was allowed to freely explore the apparatus for $10 \mathrm{~min}$. The session was repeated after $6 \mathrm{~h}$. The exploration was videotaped and the amount of time spent in each compartment was determined in order to assess the unconditioned preference. Animals showing a strong unconditioned preference $(>570$ s), i.e. less than $5 \%$, were discarded.
Place preference conditioning was conducted using an unbiased procedure. In each experimental group, half of the animals received cocaine $(30 \mathrm{mg} / \mathrm{kg}$ ip) in the spontaneously preferred compartment and the other half in the nonpreferred compartment. Immediately after the cocaine injection, each mouse was confined to the drug-paired compartment for $30 \mathrm{~min}$. After a 6-h washout period, they were administered with saline solution and confined to the other compartment for $30 \mathrm{~min}$. This procedure was repeated during four days (days 2-5). On day 6 a measure of the postconditioning score was determined in a 10-min duration free exploration session. The exploration was videotaped and the amount of time spent in each compartment was determined. The conditioned score represented the difference in time spent in the drug-paired compartment between the post and pre-conditioning sessions.

Extinction of the conditioned place preference was conducted between days 8 to 11 . Each animal was administered saline solution and confined to the drug-paired compartment for $30 \mathrm{~min}$. After a 6-h washout period, they were again administered saline solution and confined to the other compartment for $30 \mathrm{~min}$. On day 12, extinction was measured in a 10-min free exploration session, exactly as for the postconditioning session. The conditioned score represented the difference in time spent in the drug-paired compartment between the extinction and pre-conditioning sessions.

Animals showing a poor conditioning (score $<60$ s) and/or extinction (score difference with conditioning $<60 \mathrm{~s}$ ) were discontinued. It represented $19 \%$ of animals (55 mice over 288). Reactivation of place preference was measured 3 days after the extinction session, using either a drug-priming procedure on day 15 or a drug-free procedure on days 15 and 16. Animals were administered ip with saline solution, cocaine $(15 \mathrm{mg} / \mathrm{kg}), \mathrm{SCH} 23,390(0.03-1 \mathrm{mg} / \mathrm{kg})$, raclopride $(0.1-1 \mathrm{mg} / \mathrm{kg}), \mathrm{U} 99,194 \mathrm{~A}(20-40 \mathrm{mg} / \mathrm{kg})$ or a combination of each dopaminergic receptor antagonists plus cocaine and immediately placed into the white compartment. After $5 \mathrm{~s}$, the doors were raised and animals were allowed to explore the apparatus for $10 \mathrm{~min}$. The conditioned score represented the difference in time spent in the drug-paired compartment between the reactivation and pre-conditioning sessions. Data from the control groups, treated with saline or cocaine (15 $\mathrm{mg} / \mathrm{kg}$ ), were pooled and presented in Fig. (1). In the drugfree procedure, animals were injected with the different drugs and confined to the drug-paired compartment for 30 min. After a 6-h washout period, they were administered saline solution and confined to the other compartment for 30 min. On day 16, without any further injection, the place preference was measured in a 10-min duration free exploration session.

\section{Elevated Plus-Maze Test}

The apparatus consisted of two open arms $(23.5 \times 8 \mathrm{~cm})$, painted white, and two enclosed arms $(23.5 \times 8 \times 20 \mathrm{~cm}$ high), painted black. The arms extended from a central platform $(8 \times 8 \mathrm{~cm})$, and the maze was elevated to a height of 50 $\mathrm{cm}$ above the floor. Animals received drug treatments 30 min before the test. Each mouse was placed at the center of the plus-maze and its exploration behavior was recorded 


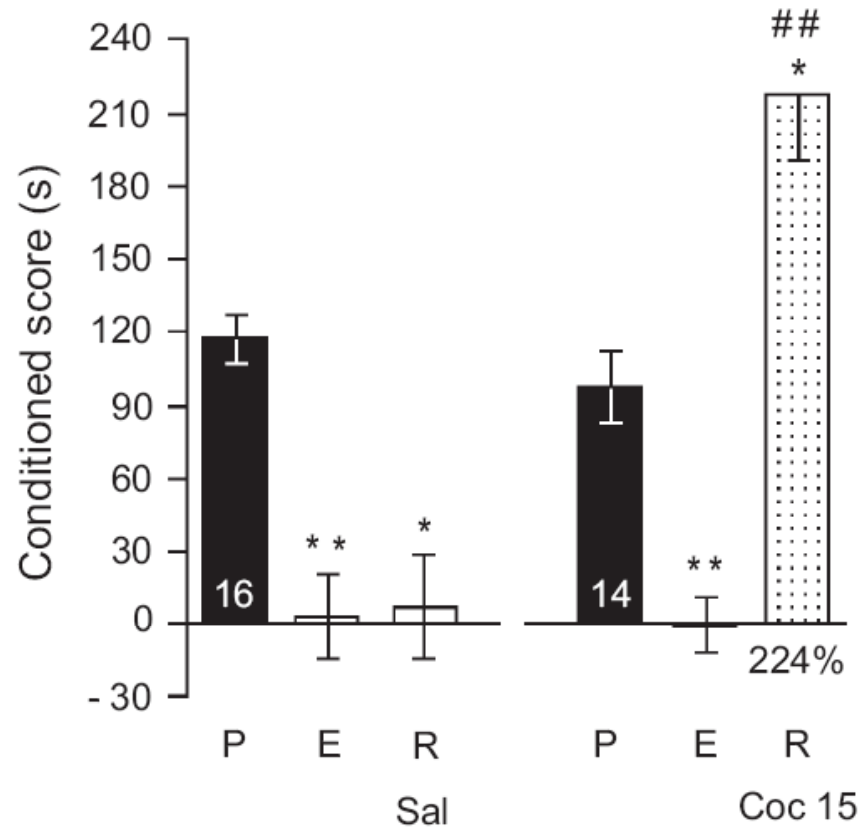

Fig. (1). Drug priming-induced reactivation of cocaine-induced CPP. CPP was established with cocaine (30 mg/kg ip) between days 2 to 5 and then extinguished with saline solution injected in the drug-paired compartment between days 7 to 10 . Reactivation was tested with ip administration of saline solution or cocaine (Coc, 15 $\mathrm{mg} / \mathrm{kg}$ ). Conditioned scores represent the difference in time spent in the drug-paired compartment between the post-conditioning $(\mathrm{P})$, extinction (E) or reactivation (R) sessions and the pre-conditioning session. The number of animals per group is indicated within the $\mathrm{P}$ column. The drug treatment used for priming is indicated in the abscissa. Repeated measures ANOVA: $F_{(2,47)}=4.88, P<0.05$ for saline; $F_{(2,41)}=15.51, P<0.0001$ for cocaine $(15)$. ${ }^{*} P<0.05$, ** $P$ $<0.01$ vs the post-conditioning measure, \#\# $P<0.01$ vs the extinction measure (Newman-Keuls' test).

during $10 \mathrm{~min}$. The time spent and the number of entries into the closed or open arms were recorded. Results were expressed as total time spent in the enclosed arms, total number of arm entries and as time spent per visit in each arm.

\section{Statistical Analyses}

The conditioned scores were expressed as mean \pm S.E.M. As they represent within-subject behavioral responses, they were considered as repeated measures among the postconditioning, extinction and reactivation sessions, using a repeated measures analysis of variance (ANOVA, $F$ values), followed by Newman-Keuls' post-hoc comparison test. Elevated plus maze data were analyzed using a non-parametric Kruskal-Wallis ANOVA ( $H$ values), followed by a Dunn's post-hoc comparison test. The criterion for statistical significance was $P<0.05$.

\section{RESULTS}

\section{Acquisition, Extinction and Reactivation of Cocaine- Induced CPP}

On day 1, the spontaneous place preference of each mouse was determined through a 10-min free exploration session. Animals were then submitted to cocaine condition- ing during four days. From day 2 to 5, cocaine injection (30 $\mathrm{mg} / \mathrm{kg}$ ip) was paired with one compartment of the CPP apparatus. The conditioned score was measured on day 6 and was about $+100 \mathrm{~s}$ (columns $\mathbf{P}$ in Figs. 1-4). The extinction of CPP was performed by pairing saline injections with the compartment previously associated with cocaine during between days 7 and 10. The place preference measured on day 11 was abolished (columns E in Figs. 1-4) and a significant decrease was measured as compared with the conditioning score, indicating that the behavioral response was extinguished. Three days later, CPP could be reactivated by a challenge drug injection. Administration of saline solution did not affect the conditioned score measured after extinction (Fig. 1). Administration of cocaine $(15 \mathrm{mg} / \mathrm{kg})$ led to the reactivation of CPP, with a score representing $224 \%$ of the post-conditioning response $(P<0.01$ vs the extinguished measure; Fig. 1).

\section{Effect of Dopamine Receptor Antagonists on Reactivation of Cocaine-Induced CPP}

The effect of the selective D1 dopamine receptor antagonist $\mathrm{SCH} 23,390$ on reactivation of cocaine-induced CPP was tested in the $0.03-1 \mathrm{mg} / \mathrm{kg}$ dose range (shown in Fig. 2A) for the three highest doses tested). At the dose of $0.3 \mathrm{mg} / \mathrm{kg}$, but not 0.1 or 1 (or 0.03 ) $\mathrm{mg} / \mathrm{kg}$, the drug provoked a highly significant reactivation, with a score representing $100 \%$ of the post-conditioning response $(P<0.01$ vs the extinguished measure; Fig. 2A). The effect of the selective D2 dopamine receptor antagonist raclopride was tested in the $0.1-3 \mathrm{mg} / \mathrm{kg}$ dose range (shown in Fig. 2B for the three lowest doses tested). At the dose of $0.3 \mathrm{mg} / \mathrm{kg}$, but not $0.1,1$ (or 3 ) $\mathrm{mg} / \mathrm{kg}$, the drug provoked a highly significant reactivation, with a score representing $93 \%$ of the post-conditioning response $(P$ $<0.01 v s$ the extinguished measure; Fig. 2B). The D3 dopamine receptor antagonist U99,194A was tested at 20 and 40 $\mathrm{mg} / \mathrm{kg}$ (Fig. 2C). The drug failed to induce any reactivation of the CPP.

The antagonists were then tested in combination with cocaine, $15 \mathrm{mg} / \mathrm{kg}$. As shown in Fig. (3A), SCH23,390 failed to affect the cocaine-induced reactivation of CPP, at $0.1 \mathrm{mg} / \mathrm{kg}$, but blocked the cocaine effect at $0.3 \mathrm{mg} / \mathrm{kg}$. In other words, the antagonist blocked the cocaine-induced reactivation and promoted reactivation when injected alone, at the same dose range. Pretreatment with the D2 or D3 dopamine receptor antagonist failed to affect the cocaine-induced reactivation of CPP (Fig. 3B,C). In particular, raclopride at $0.3 \mathrm{mg} / \mathrm{kg}$ induced CPP reactivation when injected alone and failed to affect the cocaine-induced reactivation.

$\mathrm{SCH} 23,390$ and raclopride injected alone at the dose of $0.3 \mathrm{mg} / \mathrm{kg}$ sustained reactivation of CPP. In order to examine if the chemical state induced in the brain by each drug was comparable with that induced by cocaine, the reactivation was tested using a drug-free procedure. After extinction, animals were again treated with each drug and confined 30 min in the drug-paired compartment. After $6 \mathrm{~h}$, animals received saline and were confined in the other compartment. After one day, the reactivation was examined using a 10-min duration, drug-free session (Fig. 4). The cocaine treatment, but not the saline treatment, was sufficient to induce reactivation, with a score representing $89 \%$ of the post- 

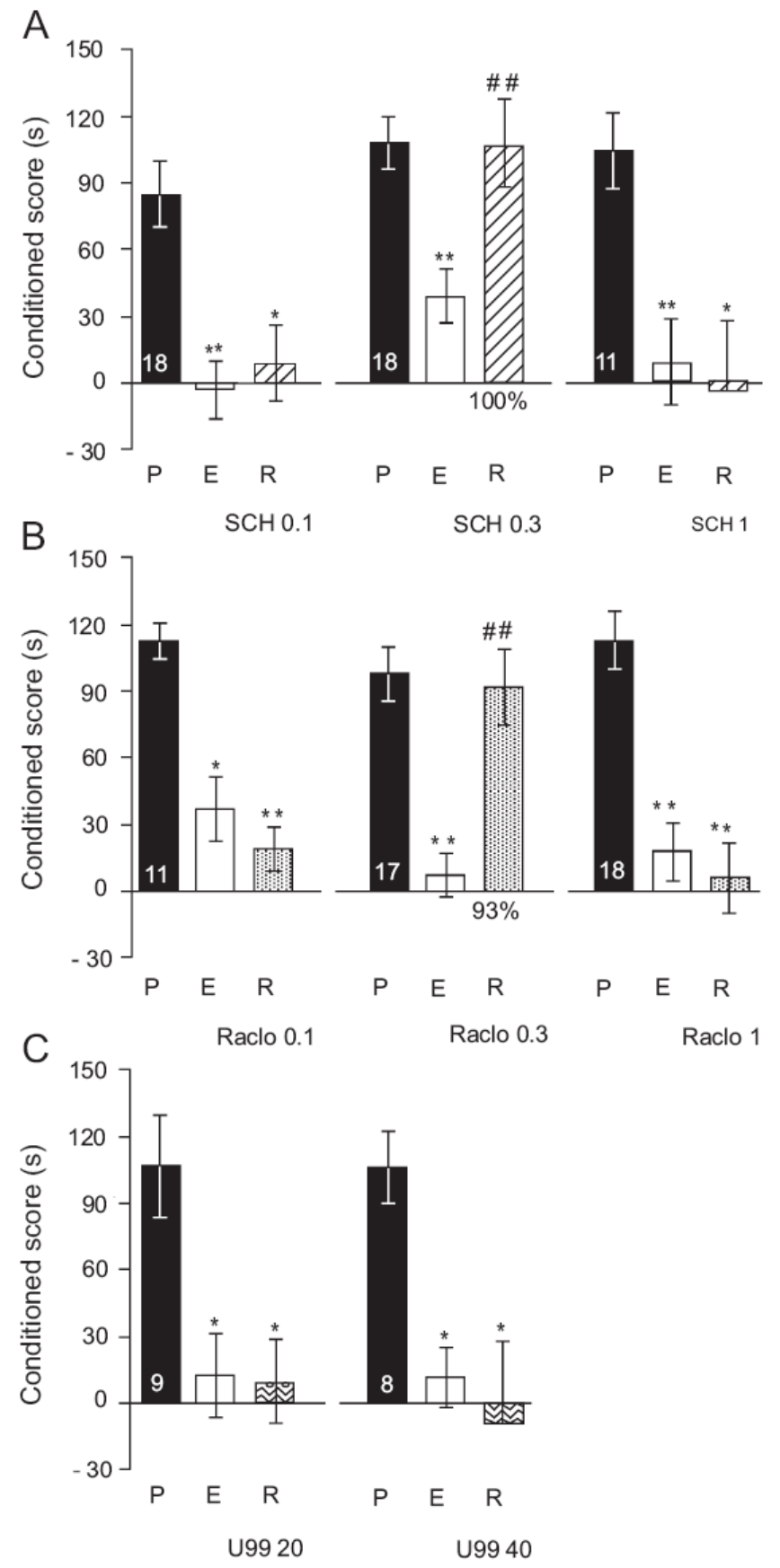

Fig. (2). Drug priming-induced reactivation of cocaine CPP: effects of dopamine receptor antagonists. CPP was established with cocaine $(30 \mathrm{mg} / \mathrm{kg}$ ip) and then extinguished with saline solution. Reactivation was tested with ip administration of (A) $\mathrm{SCH} 23,390$ $(\mathrm{SCH}, 0.1-1 \mathrm{mg} / \mathrm{kg})$; (B) raclopride (Raclo, 0.1-1 mg/kg); or $(\mathbf{C})$ U99,194A (U99, 20-40 mg/kg). Conditioned scores represent the difference in time spent in the drug-paired compartment between the post-conditioning $(\mathrm{P})$, extinction $(\mathrm{E})$ or reactivation $(\mathrm{R})$ sessions and the pre-conditioning session. The number of animals per group is indicated within the $\mathrm{P}$ bars. Repeated measures ANOVA: $F_{(2,53)}=$ $5.26, P<0.05$ for $\mathrm{SCH}(0.1) ; F_{(2,53)}=4.03, p<0.05$ for $\mathrm{SCH}(0.3)$; $F_{(2,32)}=4.96, P<0.05$ for $\mathrm{SCH}(1) ; F_{(2,32)}=12.58, P<0.001$ for Raclo $(0.1) ; F_{(2,50)}=5.17, p<0.05$ for Raclo $(0.3) ; F_{(2,53)}=13.07, P$ $<0.0001$ for Raclo (1); $F_{(2,26)}=4.94, P<0.05$ for U99 $(20) ; F_{(2,23)}$ $=4.57, p<0.05$ for U99 (40). ${ }^{*} P<0.05,{ }^{*} P<0.01 v s$ the postconditioning measure, \#\# $P<0.01$ vs the extinction measure (Newman-Keuls' test).
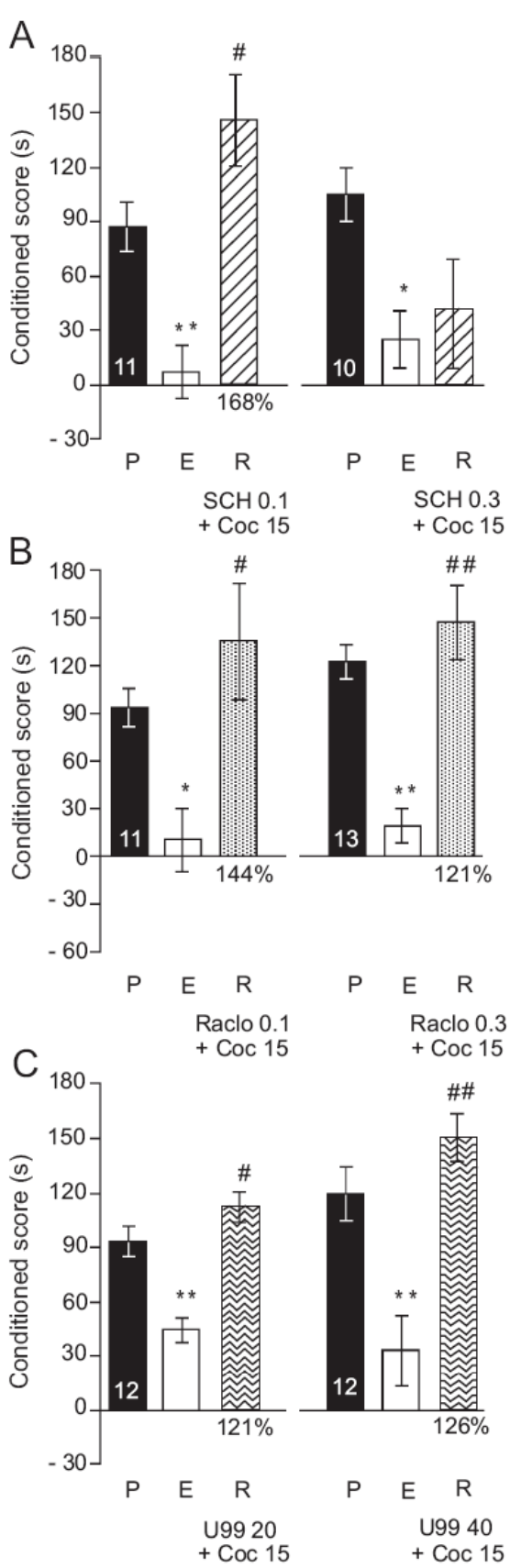

Fig. (3). Drug priming-induced reactivation of cocaine CPP: effects of co-administration of cocaine and dopamine receptor antagonists. CPP was established with cocaine $(30 \mathrm{mg} / \mathrm{kg}$ ip) and then extinguished with saline solution. Reactivation was tested with ip administration of: (A) cocaine $(15 \mathrm{mg} / \mathrm{kg})$ plus $\mathrm{SCH} 23,390(\mathrm{SCH}$, $0.1-0.3 \mathrm{mg} / \mathrm{kg})$; (B) cocaine $(15 \mathrm{mg} / \mathrm{kg}$ ) plus raclopride (Raclo, 0.1 $0.3 \mathrm{mg} / \mathrm{kg}$ ); or (C) cocaine (15 mg/kg) plus U99, 194A (U99, 20-40 $\mathrm{mg} / \mathrm{kg}$ ). Conditioned scores represent the difference in time spent in the drug-paired compartment between the post-conditioning $(\mathrm{P})$, extinction $(\mathrm{E})$ or reactivation $(\mathrm{R})$ sessions and the pre-conditioning session. The number of animals per group is indicated within the $\mathrm{P}$ column. Repeated measures ANOVA: $F_{(2,32)}=5.14, P<0.005$ for $\mathrm{SCH}(0.1)+\mathrm{Coc}(15) ; F_{(2,29)}=3.38, P<0.05$ for $\mathrm{SCH}(0.3)+\mathrm{Coc}$ $(15) ; F_{(2,32)}=3.60, P<0.05$ for Raclo $(0.1)+\operatorname{Coc}(15) ; F_{(2,38)}=$ 7.64, $p<0.01$ for Raclo $(0.3)+\operatorname{Coc}(15) ; F_{(2,35)}=4.71, P<0.05$ for U99 $(20)+\operatorname{Coc}(15) ; F_{(2,35)}=10.76, p<0.001$ for U99 $(40)+\operatorname{Coc}$ (15). ${ }^{*} P<0.05, * * P<0.01 v s$ the post-conditioning measure, \#\# $P<0.01 v s$ the extinction measure (Newman-Keuls' test). 
A

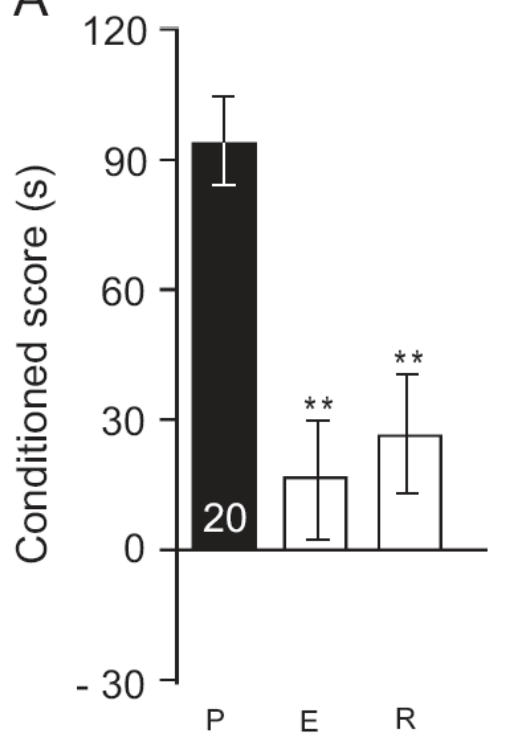

Sal

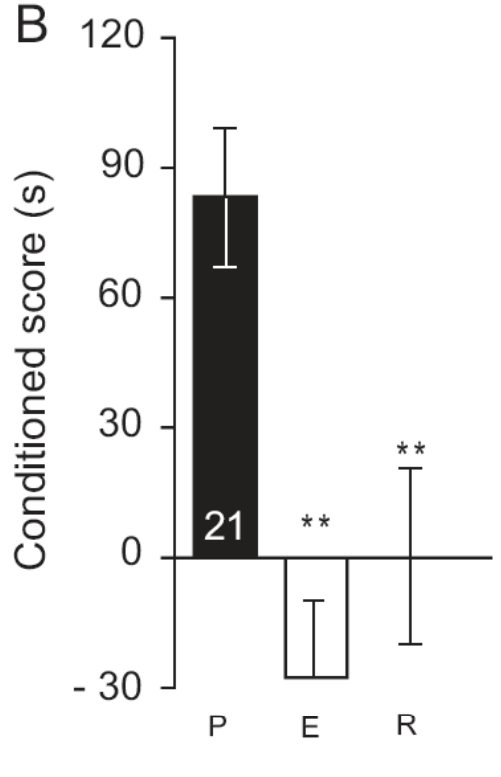

$\mathrm{SCH} 0.3$

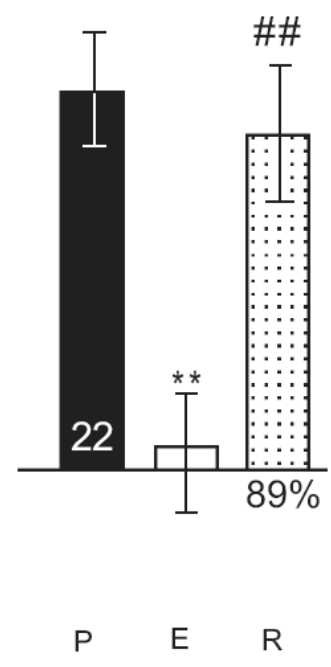

Coc 15

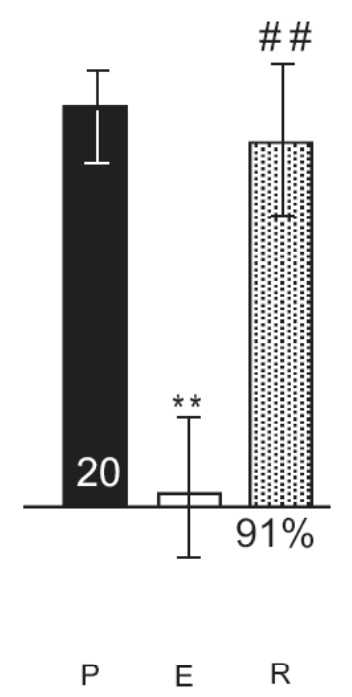

Raclo 0.3

Fig. (4). Reactivation of cocaine CPP under a drug-free procedure. CPP was established with cocaine $(30 \mathrm{mg} / \mathrm{kg}$ ip) and then extinguished with saline solution. On day 15 , animals were treated with: (A) saline or cocaine $(15 \mathrm{mg} / \mathrm{kg}),($ B) SCH 23,390 or raclopride $(0.3$ $\mathrm{mg} / \mathrm{kg}$ ) and confined $30 \mathrm{~min}$ in the previously drug paired compartment. After $6 \mathrm{~h}$, mice were treated with saline and confined in the opposite compartment. Reactivation was tested on day 16 without drug injection. Conditioned scores represent the difference in time spent in the drug-paired compartment between the postconditioning $(\mathrm{P})$, extinction $(\mathrm{E})$ or reactivation $(\mathrm{R})$ sessions and the pre-conditioning session. The number of animals per group is indicated within the $\mathrm{P}$ column. Repeated measures ANOVA: $F_{(2,59)}=$ 7.67, $P<0.01$ for saline; $F_{(2,65)}=7.32, P<0.01$ for cocaine; $F_{(2,59)}$ $=6.61, p<0.01$ for $\operatorname{SCH}(0.3) ; F_{(2,59)}=5.98, p<0.01$ for Raclo (0.3). ${ }^{* *} P<0.01 v s$ the post-conditioning measure, \#\# $P<0.01 v s$ the extinction measure (Newman-Keuls' test).

conditioning response $(P<0.01 v s$ the extinguished measure; Fig. 4A). The raclopride treatment, but not the

$\mathrm{SCH} 23,390$ treatment, provoked reactivation with a score representing $91 \%$ of the post-conditioning response $(P<$ $0.01 v s$ the extinguished measure; Fig. 4B), an observation that could be interpreted as raclopride but not $\mathrm{SCH} 23,390$ generalizing with the chemical state induced by cocaine.

\section{Anxiety State of Animals During Reactivation of Co- caine-Induced CPP}

The anxiety state of animals submitted to cocaine conditioning, extinction phase and $\mathrm{SCH} 23,390$ - or raclopridetreatment reactivation phase was tested one day after reactivation using the elevated plus-maze procedure, under the same drug dose regimen. As shown in Fig. (5), the SCH23,390 treatment resulted, at the doses of 0.3 and $1 \mathrm{mg} / \mathrm{kg}$ in significant increases in the total time spent in the enclosed arms and in the time spent in the enclosed arms per visit (Fig. 5A,C). At $1 \mathrm{mg} / \mathrm{kg}$, the drug induced an increased of time spent in the enclosed arms together with a decrease of the time spent in the open arms (Fig. 5C). At all doses tested, the drug induced a decrease in global exploration as shown by significant reductions in the total number of arm entries (Fig. 5B). The raclopride treatment induced significant variations only at the highest dose tested: a decrease in exploration (Fig. 5B), which resulted in increases in the time, spent per visit in both the open and enclosed arms (Fig. 5C).

We finally tested whether a co-treatment with cocaine could attenuate the anxiogenic effect of $\mathrm{SCH} 23,390$. As shown in Fig. (6), cocaine (15 mg/kg) failed to significantly affect the behavioral parameters in mice that underwent CPP reactivation. A tendency towards decrease time in the enclosed arms (Fig. 6A), increase in total number of arm entries (Fig. 6B) and decreases in tuime spent per visit in the enclosed arm (Fig. 6C) were observed suggesting a mild anxiolytic effect of the drug, but no significant effect was observed. SCH23,390 (0.3 $\mathrm{mg} / \mathrm{kg})$ induced significant increases in the total time and time spent per visit in the enclosed arms (Fig. 6A, C) and a significant reduction in the total number of arm entries (Fig. 6B). These effects were corrected by the co-treatment with cocaine, with significant difference for the duration parameters (Fig. 6A, C).

\section{DISCUSSION}

In the present study, we examined the involvement of D1 3 receptors in the reactivation of cocaine-induced CPP in mice. Animals were conditioned with cocaine to elicit a place preference response, which was then extinguished by substituting saline for cocaine before confinment in the drugpaired compartment. CPP reactivation was then induced by a priming injection of cocaine [8-11]. Few studies addressed the involvement of dopaminergic receptors in CPP reactivation. The first, and putatively most surprising, result in our study is that, at low dose, both D1 and D2 antagonists provoked CPP reactivation by themselves. When injected as pre-treatment before cocaine, the D1 antagonist SCH23,390 blocked the cocaine-induced CPP reactivation at the same dose as it promoted CPP reinstatement by itself. This observation strongly suggested that $\mathrm{SCH} 23,390$ alone could induce a state promoting CPP reactivation of different nature from the cocaine state, since co-administration of the two drugs at their effective dosage resulted in a lack of effect. Blockade of D2 receptors led to different observations. In- 

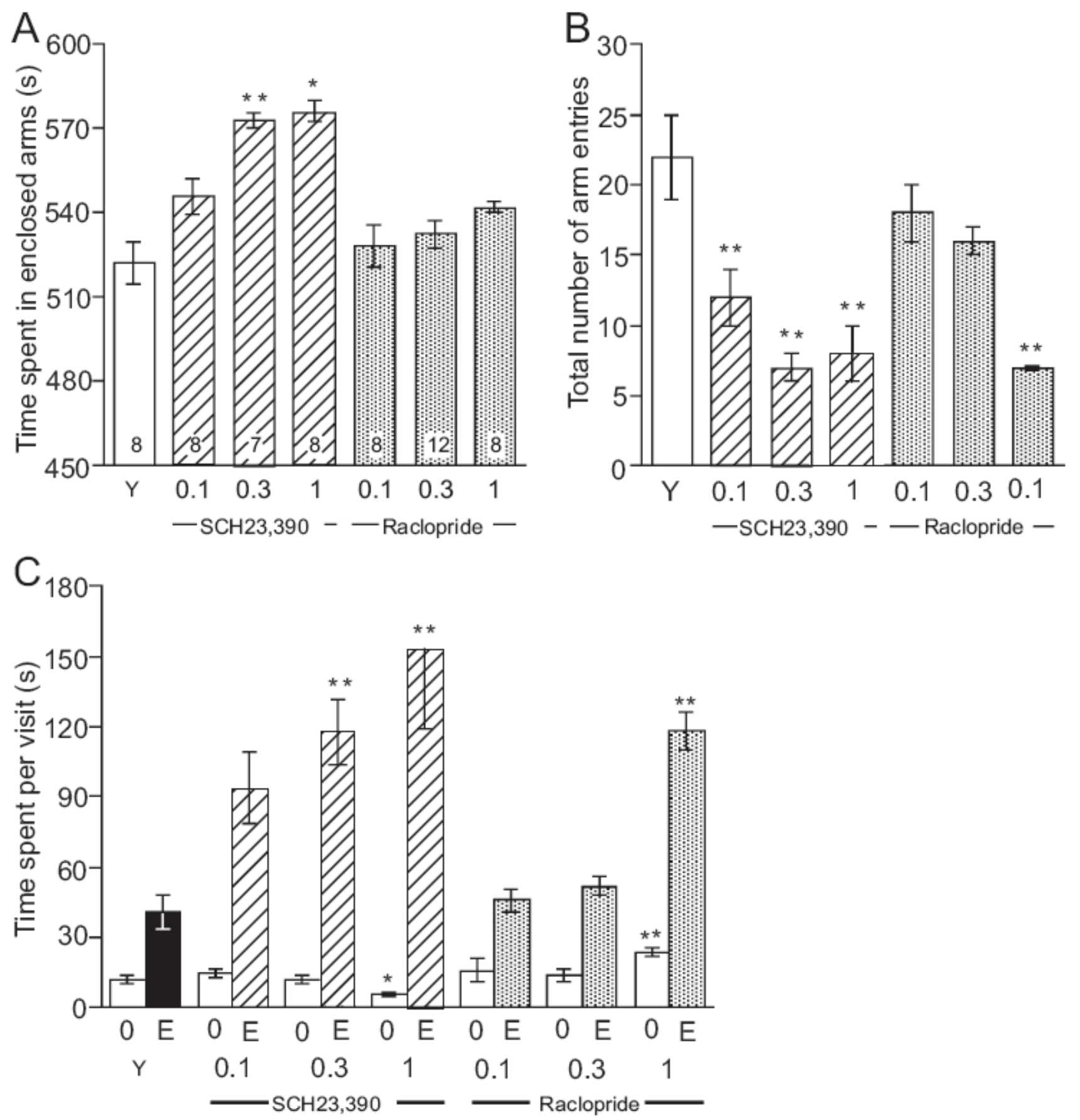

\section{Drug treatment $(\mathrm{mg} / \mathrm{kg}$ ip)}

Fig. (5). Effects of SCH23,390 and raclopride on the anxiety state of mice that underwent reactivation of cocaine-induced CPP. CPP was established with cocaine $(30 \mathrm{mg} / \mathrm{kg}$ ip) and then extinguished with saline solution. Reactivation was tested with ip administration of $\mathrm{SCH} 23,390$ or raclopride $(0.1-0.3 \mathrm{mg} / \mathrm{kg})$. After $24 \mathrm{hr}$, animals were treated again with the same dose of compounds and examined in the elevated plus-maze during 10 min: (A) time spent in the enclosed arms; (B) total number of arm entries; (C) time spent in each arm $(\mathrm{O}$, open; E, enclosed) per visit. The number of animals per group is indicated within the bars in (A). Kruskal-Wallis ANOVA: $H=17.37, P<0.01$ in (A); $H=34.83, P<0.0001$ in (B); $H=22.98, P<0.001$ for open arms and $H=34.78, P<0.0001$ for enclosed arms in $(\mathrm{C})$. ${ }^{*} P<0.05, * * P$ $<0.01$ vs the vehicle-treated group (Dunn's test).

jection of raclopride also provoked CPP reactivation when injected alone, but the pretreatment failed to affect the priming cocaine response. Therefore, the two dopamine receptor antagonists differently affected the CPP reactivation response.
Dopamine D1 receptors have been involved in acquisition and expression of cocaine appetitive properties $[4,15$, 16]. More relevant, the effect of in situ administration of 

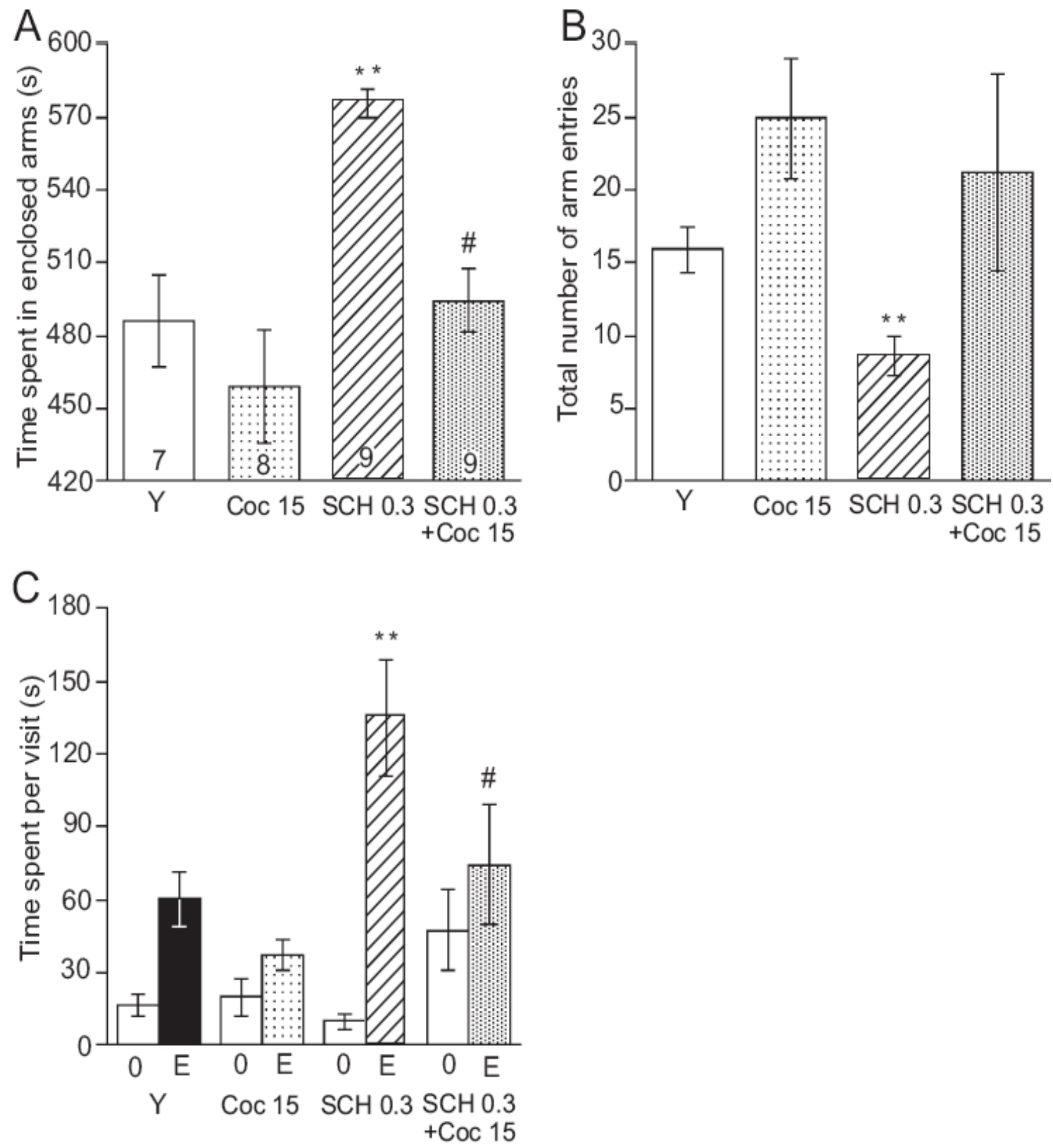

\section{Drug treatment $(\mathrm{mg} / \mathrm{kg}$ ip)}

Fig. (6). Effects of a co-treatment with SCH23,390 and cocaine on the anxiety state of mice that underwent reactivation of cocaine-induced CPP. CPP was established with cocaine ( $30 \mathrm{mg} / \mathrm{kg}$ ip) and then extinguished with saline solution. Reactivation was tested with ip administration of SCH23,390 $(0.3 \mathrm{mg} / \mathrm{kg})$ and/or cocaine $(15 \mathrm{mg} / \mathrm{kg})$. After $24 \mathrm{hr}$, animals were treated again with the same dose of compounds and examined in the elevated plus-maze during 10 min: (A) time spent in the enclosed arms; (B) total number of arm entries; (C) time spent in each arm (O, open; E, enclosed) per visit. The number of animals per group is indicated within the bars in (A). Kruskal-Wallis ANOVA: $H=$ $11.74, P<0.01$ in (A); $H=9.80, P<0.05$ in (B) $H=5.28, P>0.05$ for open arms and $H=12.28, P<0.01$ for enclosed arms in $(\mathbf{C})$. ** $P<$ $0.01 v s$ the vehicle-treated group, $\# P<0.05$ s the cocaine-treated group (Dunn's test). 
$\mathrm{SCH} 23,390$ was examined in cocaine priming. First, the drug injection into the medial prefrontal cortex blocked both stress- and cocaine-induced CPP reactivation [17]. Second, the drug injection into the medial nucleus accumbens shell attenuated the cocaine priming-induced reinstatement of drug seeking in rats [18]. However, self-administration studies showed that not only D1 receptor antagonists but also agonists attenuated the reinstatement of drug-seeking behavior induced by priming dose of cocaine [19-21]. It is therefore not clearly understood whether stimulation or blockade of D1 receptors is inhibitory in relapse to cocaine-seeking behavior. Furthermore, the molecular mechanism underlying dopamine-mediated incentive learning involves rewardinduced dopamine release, stimulation of D1-like receptors and activation of the cAMP/PKA cascade leading to the functional modification of the cortico-striatal glutamatergic synapses activated by the stimuli encountered in close temporal contiguity with reward [22]. Therefore, D1 antagonists have been shown to disrupt appetitive learning $[22,23]$, an effect supposed to impair context-induced relapse to drug seeking, in contradiction with our present observation. We suggest that different pharmacological actions at D1 receptors may result in drug seeking. Indeed, we observed that $\mathrm{SCH} 23,390$ induced in mice a strong anxiogenic-like response in the elevated plus-maze test, at the same dose as it promoted CPP reactivation. Dopaminergic mechanisms have been involved in anxiogenic-like responses, but measures were done on animals treated with amphetamine or dopamine reuptake inhibitors [24, 25], and not in cocainewithdrawn animals. We indeed report that cocaine-treated mice receiving acute injection of the D1 receptor antagonist also developed an anxiogenic state. CPP reactivation was observed at the same dose, although higher doses of the compound still maintained a strong anxious state. This suggest that, at the lowest dose, the anxious state and CPP apparatus context may be sufficient to sustain recall of the cocaine conditioning stimulus leading to CPP reactivation. Whether psychological or pharmacological reasons are involved in the discrepancy observed at higher doses remain to be explained. We measured that the co-treatment with cocaine resulted in an attenuation of the anxious state. Moreover, it is possible that co-treatment with cocaine also resulted in disruption of the cocaine-induced retrieval of appetitive learning and therefore maintenance in the extinguished CPP state. In summary, we conclude that blockade of D1 receptors induces an anxiogenic-like state, that promoted CPP reactivation when animals were placed in the context, suggesting that animals developed a psychological state underlying CPP reactivation that could be regarded as a 'cocaine craving CPP reactivation'. This state could indeed be compensated by co-administration of cocaine.

Long-term potentiation (LTP) is blocked by D1 antagonists [26, 27], but is enhanced by D2 antagonists and in D2 receptor knockout mice $[28,29]$. These observations result from opposing effects of D1 and D2 receptors on intracellular cascades that lead to phosphorylation of the $32 \mathrm{kDa}$ dopamine and cAMP-regulated phosphoprotein (DARPP-32). D1 receptor activation induces a G-protein-mediated increase of adenylyl cyclase activity, increases cAMP formation, stimulates protein kinase $\mathrm{A}$ and phosphorylates DARPP-32 [30, 31]. D2 agonists produce opposite effect on DARPP-32 activation, both by reducing adenylyl cyclase activity and calcineurin activation [31, 32]. Therefore, via opposing effects on the activation state of DARPP-32, D1 receptor activation induces and D2 receptor activation inhibits LTP. Consequently, D1 and D2 receptor antagonism produce opposite effects on learning, with D1 blockade disrupting and D2 blockade facilitating learning. An evidence was brought by Eyny \& Horvitz [33] using rats trained to enter a food compartment during pellet presentation. Animals received tone-food pairings under the influence of $\mathrm{SCH} 23,390$ or raclopride. On a drug-free test day $24 \mathrm{hr}$ later, $\mathrm{SCH} 23,390$-treated animals showed reduced head entries in response to the tone compared with vehicle controls, whereas raclopride-treated animals showed increased head entries. Under a conditioned approach paradigm, D1 and D2 receptor antagonists disrupt and promote learning, respectively, as predicted by their effects on neuronal plasticity [34]. Consequently, as CPP reactivation is based on incentive learning retrieval, that could, for instance, be induced by presentation of the drug-associated context, learning effects of dopamine antagonists must be considered. Particularly, since in the drug-free paradigm, a learning facilitating effect of raclopride is likely to explain its ability to induce CPP reactivation.

A state-dependent learning hypothesis may also account for the raclopride-induced CPP reactivation. The pharmacological state induced by acute blockade of D2 auto-receptor may be very similar to the chemical state induced by the repeated injection of cocaine, both resulting in indirect dopaminergic agonist actions. This point has to be particularly examined using adequate behavioral procedures as reported by Bruins-Slot et al. [34] or Romieu et al. [35], but it may account for the efficacy of the memory facilitation induced by the drug.

Administration of the D3 receptor antagonist U99,194A failed to be effective alone or to modify the cocaine-induced CPP reactivation. A role of $\mathrm{D} 3$ receptor has been proposed on acquisition or expression of CPP. The D3 receptor antagonist SB-277011-A or the partial D3 agonist BP 897 dose-dependently attenuated the cocaine-induced CPP in rats $[6,7]$. In particular, BP 897 impaired both acquisition and expression of CPP [7]. Duarte et al. [7] proposed that the D3 receptors are likely to be involved in the perception of the rewarding value of cocaine and cocaine-paired cues. However, an extensive study examined the involvement of the D3 receptor in the cocaine self-administration paradigm [36]. The D3 antagonists SB-277011 and U-99,194A failed to influence the rate of self-administration. The D3 selective agonist PD-128907 and the less selective 7-OH-DPAT caused significant decrease in lever-pressing and the partial agonist BP-897 evoked slight but significant increase in selfadministration. In view of the moderate intensities of the effects, the authors concluded that acute inhibition or stimulation of the D3 receptor does not appear to exert considerable influence on the acute reinforcing effect of cocaine [36]. We report in the present study that the D3 receptor also failed to be involved in the CPP reactivation, and therefore in the learning retrieval sustaining the incentive motivational processes.

The reactivation of CPP could be sustained by different psychological drives. The cocaine priming injection is believed to promote retrieval of the drug-paired stimulus asso- 
ciation, through mechanism of action underlying for instance state dependent learning, and this effect could be mediated, as least in part, by the mesocorticolimbic system which is a important brain target of cocaine, and our results suggest that D2 receptors constitute an important factor in this way. Another possible mechanism leading to reactivation of place preference can correspond to a behavioral compensatory response to stressful- or anxiogenic-like effect of a given compound. This aspect can be viewed as closely related to stress-induced reinstatement of cocaine self-administration. It could be suggested that animals exposed to stressful or anxiogenic situations re-display cocaine-related behaviors (place preference, selfadministration) after an extinction phase because of a particular effect of these situations on mesocorticolimbic neurons and their post-synaptic D1 receptor. In this way, the main question concerns the identity of brain structures involved in this behavior. Amygdala or prefrontal cortex could be a good candidate because in both structures, dopamine and norepinephrine systems interact to modulate behavioral responses to stress.

\section{ACKNOWLEDGEMENTS}

We thank Dr Rémi Martin-Fardon (The Scripps Research Institute, La Jolla, CA, USA) for helpful comments on the data and manuscript. This work was supported by CNRS.

\section{REFERENCES}

[1] Weiss, F.; Maldonado-Vlaar, C.S.; Parsons, L.H.; Kerr, T.M.; Smith, D.L.; Ben-Shahar, O. Proc. Natl. Acad. Sci. USA, 2000, 97, 4321.

[2] Weiss, F.; Martin-Fardon, R.; Ciccocioppo, R.; Kerr, T.M.; Smith, D.L.; Ben-Shahar, O. Neuropsychopharmacology, 2001, 25, 361.

[3] Shaham, Y.; Shalev, U.; Lu, L.; de Wit, H.; Stewart, J. Psychopharmacology, 2003, 168, 3-20.

[4] Cervo, L.; Samanin, R. Brain Res., 1995, 673, 242.

[5] Nazarian, A.; Russo, S.J.; Festa, E.D.; Kraish, M.; Quinones-Jenab, V. Brain Res. Bull., 2004, 63, 295.

[6] Vorel, S.R.; Ashby, C.R.; Paul, M.; Liu, X.; Hayes, R.; Hagan, J.J.; Middlemiss, D.N.; Stemp, G.; Gardner, E.L. J. Neurosci., 2002, 22, 9595.

[7] Duarte, C.; Lefebvre, C.; Chaperon, F.; Hamon, M.; Thiebot, M.H. Neuropsychopharmacology, 2003, 28, 1903.

[8] Mueller, D.; Stewart, J. Behav. Brain Res., 2000, 115, 39

[9] Itzhak, Y.; Martin, J.L. Neuropsychopharmacology, 2002, 26, 130.
[10] Szumlinski, K.K.; Price, K.L.; Frys, K.A.; Middaugh, L.D. Behav. Brain Res., 2002, 136, 151.

[11] Romieu, P.; Meunier, J.; Garcia, D.; Zozime, N.; Martin-Fardon, R.; Bowen, W.D.; Maurice, T. Psychopharmacology, 2004, 175, 154.

[12] Romieu, P.; Martin-Fardon, R.; Maurice, T. Neuroreport, 2000, 11, 2885.

[13] Romieu, P.; Phan, V.L.; Martin-Fardon, R.; Maurice, T. Neuropsychopharmacology, 2002, 26, 444.

[14] Romieu, P.; Martin-Fardon, R.; Bowen, W.D.; Maurice, T. J. Neurosci., 2003, 23, 3572 .

[15] Baker, D.A.; Khroyan, T.V.; O'Dell, L.E.; Fuchs, R.A.; Neisewander, J.L. J. Pharmacol. Exp. Ther., 1996, 279, 392.

[16] Baker, D.A.; Fuchs, R.A.; Specio, S.E.; Khroyan, T.V.; Neisewander, J.L. Synapse, 1998, 30, 181.

[17] Sanchez, C.J.; Bailie, T.M.; Wu, W.R.; Li, N.; Sorg, B.A. Neuroscience, 2003, 119, 497.

[18] Anderson, S.M.; Bari, A.A.; Pierce, R.C. Psychopharmacology, 2003, 168, 132 .

[19] Self, D.W.; Barnhart, W.J.; Lehman, D.A.; Nestler, E.J. Science, 1996, 271, 1586 .

[20] De Vries, T.J.; Schoffelmeer, A.N.; Binnekade, R.; Vanderschuren, L.J. Psychopharmacology, 1999, 143, 254.

[21] Khroyan, T.V.; Barrett-Larimore, R.L.; Rowlett, J.K.; Spealman, R.D. J. Pharmacol. Exp. Ther., 2000, 294, 680.

[22] Beninger, R.J.; Miller, R. Neurosci. Biobehav. Rev., 1998, 22, 335.

[23] Azzara, A.V.; Bodnar, R.J.; Delamater, A.R.; Sclafani, A. Pharmacol. Biochem. Behav., 2001, 68, 709.

[24] Simon, P.; Panissaud, C.; Costentin, J. Pharmacol. Biochem. Behav., 1993, 45, 685.

[25] Cancela, L.M.; Basso, A.M.; Martijena, I.D.; Capriles, N.R.; Molina, V.A. Brain Res., 2001, 909, 179.

[26] Calabresi, P.; Gubellini, P.; Centonze, D.; Picconi, B.; Bernardi, G.; Chergui, K.; Svenningsson, P.; Fienberg, A.A.; Greengard, P. J. Neurosci., 2000, 20, 8443 .

[27] Kerr, J.N.; Wickens, J.R. J. Neurophysiol., 2001, 85, 117.

[28] Calabresi, P.; Saiardi, A.; Pisani, A.; Baik, J.H.; Centonze, D.; Mercuri, N.B.; Bernardi, G.; Borrelli, E. J. Neurosci., 1997, 17, 4536.

[29] Yamamoto, Y.; Nakanishi, H.; Takai, N.; Shimazoe, T.; Watanabe, S.; Kita, H. Neuroscience, 1999, 91, 59.

[30] Hemmings, H.C.; Greengard, P.; Tung, H.Y.; Cohen, P. Nature, 1984, 310, 503.

[31] Nishi, A.; Snyder, G.L.; Greengard, P. J. Neurosci., 1997, 17, 8147.

[32] Greengard, P.; Allen, P.B.; Nairn, A.C. Neuron, 1999, 23, 435.

[33] Eyny, Y.S.; Horvitz, J.C. J. Neurosci., 2003, 23, 1584.

[34] Bruins-Slot, L.A.; Piazza, P.V.; Colpaert, F.C. Eur. J. Neurosci., 1999, 11, 4081.

[35] Romieu, P.; Lucas, M.; Maurice, T. Neuropsychopharmacology, 2006, 31, 1431.

[36] Gal, K.; Gyertyan, I. Brain Res. Bull., 2003, 61, 595. 